\title{
Dry Grasslands Database of Central Italy
}

\author{
Laura Facioni, Eva Del Vico, Leonardo Rosati, Sabina Burrascano, Agnese Tilia \& Carlo \\ Blasi
}

\begin{abstract}
We stored original and published phytosociological relevés of semi-natural dry grasslands sampled in different mountain ranges in central Italy (Apennines and anti-Apennines ranges). A total of 762 relevés were stored in a TURBOVEG database. The data spans from 1982 to present. The database has a geographical special focus on the Tyrrhenian district of central Italy and it has been designed to order improve the synecological and syntaxonomical knowledge of dry grasslands. The surveyed grasslands are pastures, characterized by different substrata (calcareous, marly-calcareous, arenaceous substrata) and macroclimatic types (Mediterranean, Submediterranean and Temperate). In physiognomic terms the majority of relevés are dominated by Bromus erectus, while a few are characterized by the dominance of Brachypodium rupestre. In syntaxonomical terms the relevés represent communities that belong to Festuco-Brometea syntaxa. A reference check-list of taxa was set up mostly following Conti et al. (2005), including several largely adopted synonymous to facilitate the correct input of relevé data. The ecological database is linked to the vascular species list, following Ellenberg indicator values modified for the Italian flora and including life forms or chorotypes. The database contains useful information to test several ecological hypotheses and to perform wide-scale vegetation classification. Furthermore it facilitates the use of vegetation-plot data for biodiversity and habitat monitoring and for land use/cover changes evaluation. This report describes the available content in the Dry Grasslands Database of Central Italy (GIVD ID EU-IT-004).
\end{abstract}

Keywords: Apennines; Festuco-Brometea communities; pasture; phytosociological relevé.

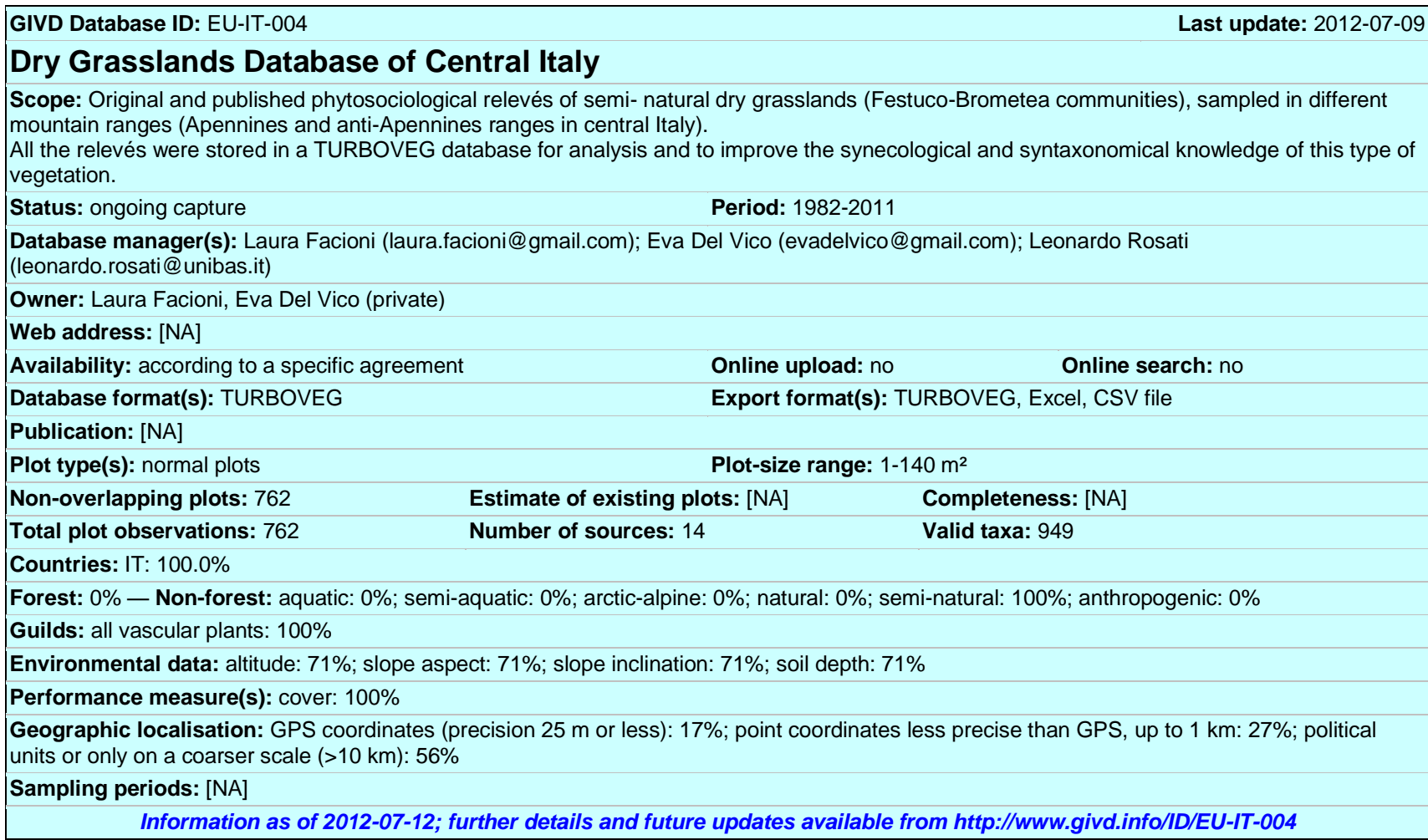

Laura Facioni* (laura.facioni@gmail.com), Eva Del Vico (evadelvico@gmail.com), Sabina Burrascano

(sabina.burrascano@uniroma1.it), Agnese Tilia (agnese.tilia@uniroma1.it), Carlo Blasi (carlo.blasi@uniroma1.it)

Department of Environmental Biology, Sapienza University of Rome, P.le Aldo Moro 5, 00185 Rome, ITALY

Leonardo Rosati (leonardo.rosati@unibas.it)

Department of Biology, Università della Basilicata, Via dell'Ateneo Lucano 10, 85100 Potenza, ITALY

*Corresponding author 